\title{
Neuropsychological prediction of dementia in Parkinson's disease
}

Florence Mahieux, Gilles Fénelon, Antoine Flahault, Marie-José Manifacier, Denyse Michelet, François Boller

\begin{abstract}
Objective-To identify neuropsychological characteristics predictive of later dementia in Parkinson's disease.

Methods-A comprehensive neuropsychological test battery was administered to a cohort of 89 initially non-demented patients with Parkinson's disease consecutively enrolled at a specialised Parkinson's disease clinic. They were reassessed after a mean of 3.5 years for the diagnosis of dementia. The Cox proportional hazards model was used to identify baseline characteristics predictive of dementia.

Results-Only four of the baseline clinical characteristics of Parkinson's disease and neuropsychological variables remained independently linked to subsequent development of dementia: the age of onset of Parkinson's disease ( $>60$ years; relative risk (RR) 4.1, 95\% confidence interval (95\% CI) $1.8-24.0, p<0.03)$, the picture completion subtest of the Wechsler adult intelligence scale (score $<10$; RR 4.9, 95\% CI 1.0-24.1, $p<0.02$ ), the interference section of the Stroop test (score $<21$; RR $3.8, \mathrm{p}=0.08$ ), and a verbal fluency task (score<9; RR 2.7, 95\% CI 0.8-9.1, p=0.09). Depressive symptoms and the severity of motor impairment were not predictive of dementia.

Conclusion-These features are different from the neuropsychological characteristics predictive of Alzheimer's dementia in healthy elderly people (mainly memory and language performance). They are in keeping with the well known specificity of the impairments in Parkinson's disease for visuospatial abilities and difficulties in inhibiting irrelevant stimuli. It is postulated that the composite nature of the picture completion subtest, involving several cognitive abilities impaired in Parkinson's disease, explains its sensitivity.
\end{abstract}

Service de Neurologie, Hôpital Tenon, Paris, France

F Mahieux

G Fénelon

MJ Manifacier

D Michelet

Antenne de

Biostatistique et

Informatique

Médicale, Hôpital

Tenon, Paris, France

A Flahault

Unité INSERM U 324, Centre Paul Broca,

Paris, France

F Mahieux

F Boller

Correspondence to: Dr F Mahieux, Service de Neurologie, Hôpital Tenon, 4 rue de la Chine, 75970

Cedex Paris, France.

Received 11 November 1996 and in final revised form 24 July 1997

Accepted 31 July 1997

\section{(F Neurol Neurosurg Psychiatry 1998;64:178-183)}

Keywords: Parkinson's disease; dementia; visuospatial; attention; frontal

Several cross sectional neuropsychological investigations of Parkinson's disease have indicated that, relative to age matched normal controls, non-demented patients with Parkinson's disease are impaired in several cognitive tasks. Precise identification of the impaired processes and their explanations in terms of cognitive models have generated a vigorous debate. ${ }^{1-3}$ However, these mild cognitive dysfunctions do not progress to full dementia in all patients with Parkinson's disease ${ }^{4-6}$; and the precise frequency ${ }^{5-18}$ and aetiology ${ }^{19-23}$ of dementia are controversial. Patients with Parkinson's disease with dementia respond poorly to treatment, often develop adverse drug reactions, and have a poorer vital prognosis than patients with Parkinson's disease without dementia. ${ }^{2}$ Early detection of preclinical signs predictive of late dementia would have considerable clinical, therapeutic, and public health value. Few studies have investigated risk factors for dementia in Parkinson's disease. ${ }^{4624-29}$ Results from these studies indicate that older age, ${ }^{2425} 28$ older age at onset, ${ }^{41625}$ more severe disease, ${ }^{1628}$ longer duration of Parkinson's disease ${ }^{4}$ poorer initial performance on the verbal scale of the Wechsler adult intelligence scale (WAIS), ${ }^{4}$ depressive symptoms, ${ }^{162428}$ psychotic adverse responses to levodopa, ${ }^{24}{ }^{28}$ cardiovascular abnormalities, ${ }^{27}$ and a family history of dementia $^{26}$ are associated with later onset of dementia. Although many of these characteristics are important and easy to record, neuropsychological studies could provide more accurate clues as to why frequent early subtle cognitive disorders do not always lead to later dementia. Jacobs et $a l^{29}$ reported that, in addition to age, disease severity, and depression, baseline performance in two verbal fluency tasks was significantly and independently associated with incident dementia. We previously performed a study ${ }^{30}$ aiming to validate a new bedside test, the mini mental Parkinson test (MMP) which allowed us to record a cohort of patients. The use in this study of a much larger neuropsychological test battery than that used by Jacobs $\mathrm{et} a{ }^{29}{ }^{29}$ and the follow up period, provided us with an opportunity to study their outcome with regard to dementia.

\section{Methods}

SUBJECTS

The patient cohort was initially selected for the MMP study. It involved 89 patients enrolled between 1990 and 1993 for the validation of two successive versions of a bedside test ${ }^{30}$ aimed at rapidly identifying specific Parkinson's neuropsychological disorders. Patients were enrolled consecutively from a specialised Parkinson's disease clinic of a hospital neurological department. All the patients were initially examined at the neurology unit of Tenon hospital, and were considered to have idiopathic Parkinson's disease. All 
were dementia free according to DSM III-R criteria, ${ }^{31}$ and were parkinsonian outpatients residing in the community. They were ineligible if they had life threatening medical conditions, other neurological conditions, or severe sensory impairment that might interfere with the tests. As major depression is a known confounding factor for neuropsychological disorders $^{32}$, patients meeting DSM III-R criteria $^{31}$ for current major depression were excluded, although patients treated with antidepressant drugs were eligible (15 cases). Depressive symptoms were assessed in all cases.

Subsequently, we decided to determine the incidence of dementia in this population. Charts were reviewed after October 1995. We required either (1) a diagnosis of dementia recorded by a neurologist according to DSMIIIR criteria ${ }^{31}$ or (2) recorded evidence of all signs and symptoms of dementia (eight cases). Follow up information was available for 86 of the 89 patients. One patient was lost to follow up, and dementia could not be assessed in two patients who died. For 43 patients data were recorded at Tenon hospital, and seven additional patients were recontacted directly. Dementia was diagnosed on the basis of a questionnaire filled in by neurologists from other hospitals in 22 cases. This questionnaire included a detailed description of all DSMIII-R criteria with special emphasis on abstract thinking, impaired judgment, and ability to manipulate acquired knowledge. In 14 cases the same questionnaire was filled in by a general practitioner and confirmed by a telephone interview with a neurologist. Finally, five patients were excluded from further analyses because, during follow up, the initial diagnosis of Parkinson's disease was found to be incorrect according to the criteria of the United Kingdom Parkinson's Disease Society Brain Bank ${ }^{33}$ (one met clinical criteria for dementia with Lewy bodies, one for progressive supranuclear palsy, two for a multisystem disorder, and one was found on review to have essential tremor).

\section{PROCEDURES}

The neuropsychological test battery consisted of the following measures: the vocabulary, similarities, comprehension, arithmetic, block design, picture completion, and picture arrangement subtests of the WAIS- $\mathrm{R}^{34}$ in which raw scores were used for statistical analysis; the digit span, and the three subtests involving sec-

Table 1 Baseline characteristics of the subjects (univariate analysis, log rank test)

\begin{tabular}{lcllll}
\hline Mean (SD) & \multicolumn{2}{c}{ Non-demented group $n=62$} & Demented group $n=19$ & p Value \\
\hline Age at baseline (y) & $65.4(10.0)$ & $72.2(8.2)$ & 0.0003 \\
Age at onset (y) & $56.9(12.3)$ & $64.2(12.2)$ & 0.005 \\
Sex (\% female) & 48.4 & 26.3 & & 0.15 \\
Disease duration (y) & $8.4(6.6)$ & $7.9(6.3)$ & 0.57 \\
Education (y) & $11.1(4.3)$ & $12.0(4.7)$ & 0.64 \\
UPDRS III & $16.5(4.9)$ & $20.1(9.5)$ & 0.01 \\
Hoehn and Yahr & $1.73(1.28)$ & $1.95(0.62)$ & 0.39 \\
CES depression & $19.8(9.5)$ & $17.3(7.7)$ & 0.58 \\
Zung anxiety & $39.4(8.3)$ & $40.1 \quad(6.9)$ & 0.28 \\
Folstein MMSE & $27.6(1.7)$ & $25.7(2.7)$ & 0.004 \\
Psychotic adverse & 9 & 10 & & 0.0006 \\
Events n (\%) & & $(14.5)$ & & $(52.6)$ &
\end{tabular}

UPDRS III = Unified Parkinson's disease rating scale: motor examination score MMS= mini mental state examination. ondary memory (logical memory, visual memory, and associate learning) in the Wechsler memory scale. ${ }^{35}$ Frontal sensitive tasks included verbal fluency (retrieval from the category of animals and the letter $M$; two 60 second trials), the words (A), colours (B), and coloured word (C) tasks of the Stroop test $^{36}$ each limited to 45 seconds, the Wisconsin card sorting test (WCST) according to Nelson's short design, ${ }^{37}$ the odd man out (OMO) test (only four successive trials) ${ }^{38}$, and the 15 object test ${ }^{39}$ the final score of which was the number of objects identified in the 120 seconds allotted. The patients also underwent the Benton line orientation test ${ }^{40}$ and Folstein's mini mental state examination (MMSE). ${ }^{41}$ All the subjects were tested by trained psychologists. We also recorded age at onset of Parkinson's disease, and the side of cardinal motor signs at diagnosis. Disease manifestations at the initial examination were scored according to the unified Parkinson's disease rating scale (UPDRS) $)^{42}$ and the Hoehn and Yahr scale. ${ }^{43}$ The Center for Epidemiologic Studies depression (CES-D) ${ }^{44}$ and Zung anxiety ${ }^{45}$ self rating scales (French translation) were filled in by the patients. Previous adverse effects of therapy (confusion or psychosis) were recorded and combined for this analysis.

\section{STATISTICAL METHODS}

We used a stepwise Cox proportional hazards model for censored data. The time from baseline to the visit at which dementia was diagnosed was used as the timing variable for Cox analyses. For patients who remained free of dementia, we used the time from baseline to the last available follow up visit. All the continuous variables at baseline (including neuropsychological performance and clinical characteristics) were dichotomised. The cut off values were the median of each index. To reduce the large number of variables, they were selected in a two step process. Firstly, each variable was compared between the patients who became demented and those who remained free of dementia in univariate analysis (by using a log rank test). All clinical and neuropsychological variables were included in this analysis, together with the MMSE orientation item. Those variables with two sided significance $(p=0.05)$ were then submitted to a Cox proportional hazards multivariate model. On the basis of previous studies ${ }^{42} 26-29$ the UPDRS items "facial mask", "bradykinesia of hands", and "speech", and the UPDRS total motor examination score, age at onset, and CES-D score were also included as covariates, whatever their level of significance in the univariate analysis. The $\mathrm{p}$ value limit for entering the covariates in the model was set at 0.10 . Hazard ratios were estimated with $95 \%$ confidence intervals (95\% CIs).

SAMPLE SIZE

As the variables submitted to the multivariate model were dichotomised with the median as cut off, the size of the exposed group was equal to that of the unexposed group for each covariable of interest. At a significance of $5 \%$ and 
Table 2 Neuropsychological characteristics of the subjects (univariate analysis, log rank test)

\begin{tabular}{lccl}
\hline Neuropsychological variable (median) & Non-demented group $n=62$ & Demented group $n=19$ & $p$ Value \\
\hline Comprehension (16) & $17.2(6.2)$ & 13.46 .2 & 0.004 \\
Arithmetic (9) & $9.7(4.7)$ & $8.9(3.7)$ & 0.57 \\
Similarities (15) & $12.7(7.9)$ & $9.8(7.7)$ & 0.12 \\
Vocabulary (40) & $38.8(14.6)$ & $39.5(15.6)$ & 0.8 \\
Completion (9) & $9.8(5.2)$ & $4.6(4.6)$ & 0.0005 \\
Block design (14) & $17.6(10.0)$ & $7.2(8.5)$ & 0.002 \\
Arrangement (2) & $5.2(4.3)$ & $2.4(2.7)$ & 0.77 \\
Span (9) & $9.1(1.8)$ & $9.1(1.5)$ & 0.009 \\
Logical memory (7.5) & $8.0(3.6)$ & $6.1(2.5)$ & 0.37 \\
Associates (13.5) & $13.6(5.5)$ & $11.4(4.8)$ & 0.03 \\
Visual memory (7) & $7.5(4.0)$ & $4.7(3.5)$ & 0.0001 \\
Stroop A (80) & $82.1(23.9)$ & $55.0(21.9)$ & 0.0002 \\
Stroop B (52) & $55.1(17.6)$ & $34.6(16.2)$ & 0.0002 \\
Stroop C (21) & $25.9(12.3)$ & $13.6(10.3)$ & 0.02 \\
WCST series (3) & $3.8(2.3)$ & $2.2(1.9)$ & 0.11 \\
WCST errors (16) & $16.0(10.4)$ & $22.5(10.2)$ & 0.12 \\
WCST perseveratives (7) & $6.6(5.7)$ & $11.1(8.7)$ & 0.34 \\
Benton line orientation (24) & $23.1(6.7)$ & $17.4(10.3)$ & 0.01 \\
Fluency animals (16) & $17.1(6.4)$ & $12.0(5.5)$ & 0.01 \\
Fluency letter M (9) & $10.1(5.6)$ & $6.4(4.5)$ & 0.003 \\
Odd man out (25) & $26.5(7.6)$ & $22.4(7.2)$ & 0.01 \\
15 objects (12) & $11.5(2.9)$ & $9.9(3.3)$ & 0.21 \\
Orientation (10) & $9.5(0.8)$ & $9.2(0.8)$ & \\
\hline
\end{tabular}

Results are presented as mean (SD).

with a power of $80 \%, 10$ events must be expected in the unexposed group to detect a relative risk $>2.5$ (three events for a relative risk $(\mathrm{RR}) \geqslant 5)$.

BMDP statistical software was used for all the analyses.

\section{Results}

Of the 89 patients originally examined, 81 were included in the analyses. Their mean (SD) age was 66.9 (10.0) years, and there were 35 women and 46 men. Their mean number of years of education was 11.3 (SD 4.4). The mean duration of Parkinson's disease was 8.3 (SD 6.5) years. The mean UPDRS motor examination score was 17.9 (SD 14.4). The mean duration of follow up was 3.5 (SD 1.5) years. A total of 19 patients became demented during the follow up period, resulting in an incidence rate of $67.2 / 1000$ person-years in this sample (Poisson 95\% CI 40.3-105.1).

Table 1 shows the baseline characteristics of the patients who did and who did not become demented. Patients who became demented were older, developed Parkinson's disease at an older age, had a higher motor examination score (UPRS III), and were more likely to have psychotic adverse events. They had a significantly lower score in Folstein's MMSE. The two groups did not differ significantly in terms of education, sex, history of smoking, Hoehn and Yahr stage, severity of facial mask and bradykinesia of hands, disease duration, or the anxiety and depression scores.

Nine of the neuropsychological variables (table 2) did not differ significantly between the two groups and were not retained for multivariate analysis (vocabulary, similarities, arith-

Table 3 Results of the Cox proportional hazards multivariate model for prediction of dementia ( 81 patients included in the analysis). The hazard risk ratio for each variable estimates its relative risk associated with a score below or above the median (in parenthesis) independently of all other variables in the model

\begin{tabular}{lllll}
\hline Variable & Coefficient & Relative risk & $95 \%$ CI & p Value \\
\hline Completion $(<10)$ & 1.5831 & 4.9 & $0.98-24.12$ & 0.03 \\
Age at onset $(>60$ years $)$ & 1.4168 & 4.1 & $1.11-15.31$ & 0.02 \\
Stroop C $(<21)$ & 1.3343 & 3.8 & $0.74-20.00$ & 0.08 \\
Letter fluency $(<9)$ & 0.9804 & 2.7 & $0.81-9.09$ & 0.09 \\
\hline
\end{tabular}

metic, span, associate memory, Benton line orientation test, WCST errors and perseverative errors, and MMSE orientation item).

When the remaining variables were submitted to the Cox regression model along with the covariates (age at onset, education, CES-D, side of onset, mask face, and psychotic adverse events), four variables remained independent predictors (table 3): age at onset $(\mathrm{p}=0.02)$, the picture completion subtest of the WAIS-R $(p=0.03)$, the coloured word part of the Stroop test $(p=0.08)$ and verbal fluency (letter $M)(p=0.09)$, although the last two were only close to significance. Table 2 presents the RR estimates. The median age at onset of Parkinson's disease was 60 years; patients with Parkinson's disease older than 60 years had a 4.1-fold higher risk of developing dementia. The median value for the WAIS-R picture completion subtest was 9.5; an observed raw score $<10$ was associated with an RR of 4.9 . The median Stroop score was 20; patients who named less than 21 colours in the third part of the Stroop test had a 3.8-fold higher risk of developing dementia. The median letter fluency score was 8.5 ; patients had a 2.7 -fold higher risk of developing dementia within three and half years if they found fewer than nine words beginning with the letter $M$ in one minute.

To assess the potential for misdiagnosis we performed the same multivariate analysis after (a) exclusion of the 14 patients in whom dementia was diagnosed by general practitioners, and (b) exclusion of the three patients with $M M S E<23$. The results were only slightly modified. The WAIS-R completion subtest and age at onset remained significant and independent predictors of dementia in the two subanalyses. Verbal fluency remained as a trend $(p=0.09)$ but the Stroop test did not in the first subanalysis; in the second the Stroop interference subtest remained as a trend $(p=0.07)$ but verbal fluency did not.

\section{Discussion}

In a sample of 81 initially non-demented patients with Parkinson's disease, we found that four baseline clinical characteristics and 
neuropsychological variables remained independently linked to subsequent development of dementia: the age of onset of Parkinson's disease ( $>60$ years), the picture completion subtest of the WAIS-R (raw score $<10$ ), the C part of the Stroop test (number of colours named $<21$ ), and a verbal fluency task (<nine words). Unlike other authors ${ }^{529}$ we found no predictive value of depressive symptoms or UPDRS motor scores. The predictive value of older age at onset has long been known. ${ }^{524}$ The predictive value of poorer performance in verbal fluency tasks was recently described by Jacobs et al. ${ }^{29}$ The use of a comprehensive neuropsychological test battery to assess a range of cognitive domains, which was not explored by Jacobs et $a l,{ }^{29}$ disclosed the higher predictive value of the picture completion subtest of the WAIS-R.

The WAIS-R picture completion subtest consists of finding, in a card series, a missing detail in a familiar picture (door handle, eyebrow in a face, dog's tracks, shadow in a landscape). The task is time limited and is known to require several cognitive abilities, such as sustained attention (for close inspection of material), shape or situation analysis (relevant to visuoperceptual abilities), and developing new strategies across different cards. All of these abilities are often impaired in Parkinson's disease. ${ }^{13} 46$ The impairment of patients with Parkinson's disease in the WAIS performance subset is well known. ${ }^{4146}$ These tests have fallen into disuse for research purposes, in favour of more comprehensive tasks attempting to examine more specific neuropsychological processes in Parkinson's disease. The fact that this test was the only one to remain a highly significantly independent predictor of later dementia could be explained by its composite nature, which may be broader than that of the other tasks in this study, rather than by the identification of a specific cognitive ability impaired early in the dementia process. This composite nature could render it especially sensitive to very mild deteriorations.

We agree with Jacobs $e t a l,{ }^{29}$ who interpreted the predictive value of impaired verbal fluency as an impairment of planning and initiating a systematic search in semantic memory rather than a primary impairment of language. They proposed to relate the discrepant findings of previous cross sectional studies on verbal fluency to differences in task instructions. Unlike them we did not give the patients cues such as superordinate categories. This could explain why the category fluency task did not remain an independent predictor of dementia in the current study. It could also be that alternating category and letter fluency tasks requires the ability to shift between mental sets, ${ }^{47}$ an ability that was explored with more specific tasks in the present study.

The Stroop test consists of three sections. ${ }^{36}$ In the first, patients are required to read aloud, as fast as possible, words (colour names) written in columns. The second section consists of series of crosses printed in coloured ink, the task being to name the ink colours as fast as possible. The third (interference) section con- sists of words (always names of colours) printed in columns, the ink colours differing from the written word (for instance word "green" printed in blue ink). The task is to name as fast as possible the ink colours, ignoring the written word. All Stroop sections reflect slowing down of information processing. The third part specifically concerns proactive interference and the ability to ignore irrelevant stimuli. Some authors have argued that the "ignoring irrelevant stimulus" dimension could be a highly specific attentional dysfunction in parkinsonian patients. ${ }^{48}$ As pointed out by Downes et $a l^{47}$ "the idea that inhibitory attentional processes are less efficient in Parkinson's disease is consistent with Hassler's ${ }^{49}$ early contention that the basal ganglia are critical for the suppression of extraneous information". In a recent study of a subgroup of parkinsonian patients showing pronounced frontal type cognitive impairment, low scores in verbal fluency and Stroop tests correlated with a severe decrease in the later component of auditory evoked potential $\mathrm{Nd} 2$, considered to reflect regulating frontal processes during selective attention. ${ }^{50}$

The lack of association between the occurrence of dementia and the UPDRS motor examination score in our sample could be explained by a much milder impairment of our patients relative to those in the study of Jacobs et $a{ }^{29}{ }^{29}$ although the duration of Parkinson's disease seems to be similar in the two samples. This finding has to be confirmed in larger studies involving a wide range of patients. Fatiguability, motor impairment, slowing down, and dyskinesia hinder in depth evaluation, especially of the most strongly impaired patients. The possibility that these physical limitations mask early deterioration cannot be ruled out. ${ }^{4}$

The lack of association between the occurrence of dementia and depressive symptoms in our sample could be due to a recruitment bias, as we excluded patients with major depression from the MMP validation study. Recent population studies showed that the prevalence of major depression, based on DSM-IIIR criteria, is lower than previously estimated $(<8 \%)$, although the prevalence of depressive symptoms is high. ${ }^{51-53}$ However, 36 patients in our study scored above the cut off for depression on the self administered CES depression scale (although this kind of scale must be interpreted cautiously in Parkinson's disease ${ }^{15}$ ), a prevalence very close to that found by Tanberg et al. ${ }^{53}$ Depression is often considered as an important factor associated with cognitive impairment in Parkinson's disease. ${ }^{54-57}$ For others, the effect of mood on the performance of cognitive tests is, at best, partial. ${ }^{58-60}$ In a recent study Tröster et $a l^{60}$ found that depression exacerbated some memory and language impairments associated with Parkinson's disease-namely, verbal fluency (category as well as letter retrieval), the Boston naming test, and logical memory. A higher prevalence of depressive symptoms in the sample of Jacobs et $a l^{29}$ could, at least in part, explain the discrepancies in the impact of 
depression and the relative importance of fluency tasks in the two studies.

The demented group in our study had a significantly lower MMSE at the first assessment, giving evidence of clear cognitive dysfunction. The dementia might thus already have begun in this group. This calls for two comments. Firstly, the MMSE is a bedside test designed to screen for Alzheimer type dementia, ${ }^{41}$ but its dependence on cultural level is well known ${ }^{6162}$ and hinders the use of a rigid cut off score. For the diagnosis of dementia in other cognitive disorders, its reliability is far from demonstrated. ${ }^{6}$ However, its worldwide use makes it convenient for grossly evaluating and comparing the global level of cognitive function in clinical samples. Secondly, patients with Parkinson's disease are not comparable with healthy subjects. Cognitive disorders present in nearly all patients with Parkinson's disease are widely described, ${ }^{6}{ }^{13}$ and Growdon and Corkin emphasised that clinically non-demented patients with Parkinson's disease may score outside the normal range on MMSE. ${ }^{63}$ The sample studied here was not composed of de novo patients (although 30 of them had less than a five year disease history at the first assessment), but was a representative sample of all patients with Parkinson's disease seen at a neurological consultation. The search for neuropsychological predictors of dementia assumes that the process responsible for dementia begins long before its full clinical expression and that mild neuropsychological disorders due to this process can be identified.

The use of DSM-IIIR criteria for the diagnosis of dementia in Parkinson's disease has been criticised $^{6}$ because of the clinical differences between Alzheimer's disease dementia and Parkinson's disease dementia. ${ }^{645}$ For instance, the primacy of memory loss seems typical of Alzheimer's disease but not Parkinson's disease, whereas disturbances of attention, motivation, accessing and manipulating knowledge, and psychomotor slowing, are typical of Parkinson's disease dementia. These differences led to the concept of subcortical dementia. ${ }^{66}$ However, the validity of this concept is still controversial. ${ }^{67-69}$ Consensus discussions on clinical criteria for the diagnosis of dementia in Parkinson's disease would be desirable, although such criteria will be difficult to establish because of the probable heterogeneity of dementia in Parkinson's disease. ${ }^{70}$ In addition, the social and clinical decline related to cognitive disorders is difficult to identify, as the motor deficit limits activities and leads to dependency. Finally, the continuous distribution of cognitive disorders in Parkinson's disease makes it difficult to identify the moment at which they are sufficient to diagnose dementia. ${ }^{71}$ No operational criteria specifically designed for Parkinson's disease dementia are available. Despite the above limitations, DSM criteria remain the best choice as they vastly improve the accuracy and consistency of dementia diagnoses. ${ }^{20}$ Finally, the fact that neuropsychological predictors of dementia in our Parkinson's disease cohort were not the same as those described as predictors of Alzheimer's disease (see next paragraph) is a good argument that DSM-IIIR criteria did not only select Alzheimer's disease.

The neuropsychological pattern characterising the preclinical stages of dementia in Parkinson's disease differed from that reported in the two papers describing the neuropsychological characteristics of preclinical dementia of the Alzheimer type in healthy elderly subjects. ${ }^{72}{ }^{73}$ Masur et $a l^{2}$ found that delayed recall in the Buschke selective reminding test, recall in the Fuld object memory evaluation, the WAIS digit symbol subtest, and a verbal fluency score at the baseline assessment identified a subgroup of healthy subjects with an $85 \%$ probability of developing dementia during the follow up period. Similarly, Jacobs $e t a l^{33}$ found that scores in the Boston naming test, immediate recall on the selective reminding test, and the WAIS-R similarities subtest were significantly and independently associated with a later diagnosis of Alzheimer's disease. The problem of preclinical detection of dementia is substantially different in Parkinson's disease and Alzheimer's disease. In the second, the key is to identify healthy elderly subjects who have subtle cognitive changes well before the overt clinical signs of dementia occur. In Parkinson's disease the problem is to select, among a broad range of neuropsychological abnormalities, those predictive of later dementia. The different cognitive profiles for preclinical dementia in Parkinson's disease and Alzheimer's disease are in keeping with the well known differences between demented patients with Parkinson's disease and those with Alzheimer's disease $^{6465}$ : the core symptoms of preclinical Alzheimer's disease involve essentially memory and language tasks, whereas the core symptoms of preclinical dementia in Parkinson's disease involve executive functions rather than memory. This may reflect different pathological substrates for the dementia syndromes associated with these two diseases. As in many clinical studies of dementia, our findings are limited by the impossibility of obtaining an aetiological diagnosis. Although 23 of the patients included in our analysis died, none underwent postmortem examination. Thus we are unable to attribute the dementia to Alzheimer's disease, diffuse Lewy bodies, or another cause, all of which could at least partially modify the neuropsychological pattern forerunning each form of dementia.

Our finding that impaired picture completion and word retrieval are predictive of subsequent dementia confirms and extends the results of Jacobs et $a .^{29}{ }^{29}$ Further studies are needed to confirm these data on different samples. However, these two simple tasks could be included routinely in the first assessment of patients with Parkinson's disease and be used as copredictors of a high risk of psychotic adverse events to therapy.

This study was supported in part by a grant from Produits Roche France (1990 Roche Prize). We are grateful to David Young for patient revision of the English.

1 Brown RG, Marsden CD. Cognitive function in Parkinson's disease: from description to theory. TINS 1991;13:21-9.

2 Dubois B, Boller F, Pillon B, Agid Y. Cognitive deficits in Parkinson's disease. In : Boller F, Grafman J, eds. Handbook of neuropsychology. Amsterdam: Elsevier, 1991;5:195-239. 
3 Taylor AE, Saint Cyr JA. The neuropsychology of Parkinson's disease. Brain Cogn 1995;28:281-96.

4 Biggins CA, Boyd JL, Harrop FM, et al. A controlled, longitudinal study of dementia in Parkinson's disease. $f$ Neuro Neurosurg Psychiatry 1992;55:566-71.

5 Marder K, Tang MX, Cote LJ, Stern Y, Mayeux R. The frequency and associated risk factors for dementia in patients
with Parkinson's disease. Arch Neurol 1995;52:695-701.

6 Mohr E, Mendis T, Grimes JD. Late cognitive changes in Parkinson's disease with an emphasis on dementia. $A d v$ Neurol 1995;65:97-113.

7 Lieberman A, Dziatolowski M, Coopersmith M, et al. Dementia in Parkinson's disease. Ann Neurol 1979;6:355-9. Brown RG, Marsden CD. How common is dementia in Parkinson's disease? Lancet 1984;i:1262-5.

9 Martilla RJ, Rinne UK. Dementia in Parkinson's disease. Acta Neurol Scand 1976;54:431-41.

10 Taylor AE, Saint Cyr JA, Lang AE. Dementia prevalence in Parkinson's disease Lancet 1985; : 1037 .

11 Lees AJ. Parkinson's disease and dementia. Lancet 1985; 43-4.

12 Rajput AH, Offord KP, Beard CM, Kurland LT. A case control study of smoking habits, dementia and other illnesses in idiopathic Parkinson's disease. Neurology 1987, 37:226-32.

13 Girotti F, Soliveri P, Carella F, et al. Dementia and cognitive impairment in Parkinson's disease. F Neurol Neurosurg Psychiatry 1988;51:1498-502.

14 Mayeux R, Stern Y, Rosenstein R, et al. An estimate of the prevalence of dementia in idiopathic Parkinson's disease. Arch Neurol 1988;45:260-2.

15 Starkstein SE, Bolduc PL, Mayberg HS, Preziosi TJ, Robinson RG. Cognitive impairments and depression in Parkinson's disease: a follow up study. $\mathcal{F}$ Neurol Neurosurg Psychiatry 1990;53:597-602.

16 Mayeux R, Denaro J, Hemenegildo N, Tang MX, Stern Y. A population-based investigation of Parkinson's disease with population-based investigation of Parkinson's dise

17 Tison F, Dartigue JF, Auriacombe S, Letenneur L, Alpérovitch A. Dementia in Parkinson's disease. A populationvitch A. Dementia in Parkinson's disease. A populationals. Neurology 1995;45:705-8.

18 Aarsland D, Tandberg E, Larsen JP, Cummings JL. Frequency of dementia in Parkinson's disease. Arch Neuro 1996;53:538-42

19 Dubois B, Hauw JJ, Ruberg M, Serdaru M, Javoy-Agid F, Agid Y. Démence et maladie de Parkinson: corrélations biochimiques et anatomo-cliniques. Rev Neurol (Paris) 1985;141:184-93.

20 Gibb WRG. Dementia and Parkinson's disease. $\mathrm{Br} f$ Psychiatry 1989;154:596-614.

21 Jellinger K. Alzheimer pathology and Parkinson's disease. Neurology 1989;39:874.

22 Gibb WRG, Lees AJ. Alzheimer pathology in Parkinson's disease. Neurology 1989;39:874-5.

23 Hughes AJ, Daniel SE, Blankson S, Lees AJ. A clinicopathologic study of 100 cases of Parkinson's disease. Arch Neurol 1993;50:140-8.

24 Guillard A, Chastang C, Fénelon G. Etude à long terme de 416 cas de maladie de Parkinson. Facteurs de pronostic et 416 cas de maladie de Parkinson. Facteurs de pronostic et
implications thérapeutiques. Rev Neurol (Paris) 1986;142: implication.

25 Ebmaier KP, Calder SA, Crawford JR, Stewart L, Besson JAO, Mutch WJ. Clinical features predicting dementia in idiopathic Parkinson's disease: a follow-up study. Neurology 1990;40:1222-4.

26 Marder K, Flood P, Cote LJ, Mayeux R. A pilot study of risk factors for dementia in Parkinson's disease. Mov Disord 1990;5:156-61.

27 Salganik I, Korczyn A. Risk factors for dementia in Parkinson's disease. Adv Neurol 1990;53:343-7.

28 Stern Y, Marder K, Tang MX, Mayeux R. Antecedent clinical features associated with dementia in Parkinson's disease. Neurology 1993;43:1690-2.

29 Jacobs DM, Marder K, Cote LJ, Sano M, Stern Y, Mayeux R. Neuropsychological characteristics of preclinical deR. Neuropsychological characteristics of preclinical de-
mentia in Parkinson's disease. Neurology 1995;45:1691-6.

30 Mahieux F, Michelet D, Manifacier MJ, Boller F, Fermanian J, Guillard A. Mini-mental Parkinson: first validation nian J, Guillard A. Mini-mental Parkinson: first validation study of a new bedside test constr

31 American Psychiatric Association. Diagnostic and statistical manual of mental disorders, 3rd ed, revised (DSM III-R). Washington, DC: American Psychiatric Association, 1987.

32 Stromgren LS. The influence of depression on memory Acta Psychiatr Scand 1977;56:109-28.

33 Hughes AJ, Daniel SE, Killford L, Lees AJ. Accuracy of clinical diagnosis of idiopathic Parkinson's disease. A clinicopathological study of 100 cases. 7 Neurol Neurosurg Psychiatry 1992;55:181-4.

34 Wechsler D. The Wechsler adult intelligence scale-revised. TE San Antonio; Psychological Corporation, 1981.

35 Wechsler D. A standardised memory scale for clinical use. $\mathcal{F}$ Psychology 1945;19:87-95.

36 Stroop J. Studies of interferences in serial verbal reactions. $\mathcal{f}$ Exp Psychol 1935;18:643-62.

37 Nelson HE. A modified card sorting test sensitive to frontal lobe defects. Cortex 1976;12:313-24.

38 Flowers KA, Robertson C. The effect of Parkinson's disease on the ability to maintain a mental set. $\mathcal{F}$ Neurol Neurosurg Psychiatry 1985;48:517-29.

39 Pillon B, Dubois B, Bonnet AM, et al. Cognitive slowing in Parkinson's disease fails to respond to levodopa treatment: the 15-objects test. Neurology 1989;39:762-8.
40 Benton AC, Varney NR, Hamsher K de S. Visuo-spatial judgement. A clinical test. Arch Neurol 1978;35:364-7.

Folstein SE, Folstein MF, McHugh PR. Mini-mental state: a practical method for grading the cognitive state of patients for the clinician. F Psychiatr Res 1975;12:189-98.
Stern MB. The clinical characteristics of Parkinson's disease and parkinsonian syndromes: diagnosis and assessment. In: Stern MB, Hurtig HI, eds. The comprehensive management of Parkinson's disease. New York: PMA, 1988:3-50.

43 Hoehn MM, Yahr MD. Parkinsonism: onset, progression and mortality. Neurology 1967;17:427-42.

44 Fuhrer R, Rouillon F. La version française de l'échelle CES-D (Center for Epidemiologic Studies-depression scale). Description et traduction de l'échelle d'autoévaluation. Psychiatry and Psychobiology 1989;4:163-6.

45 Zung WWK. A rating instrument for anxiety disorders. Psychosomatics 1971;12:371-9.

46 Guillard A, Fénelon G, Mahieux F. Les altérations cognitives au cours de la maladie de Parkinson. Rev Neurol (Paris) 1991;147:337-55.

47 Downes JJ, Sharp HM, Costall BM, Sagar HJ, Howe J. Alternating fluency in Parkinson's disease. Brain 1993;116: 887-902.

48 Downes JJ, Roberts AC, Sahakian BJ, Evenden JL, Morris RG, Robbins TW. Impaired extradimensional shift performance in medicated and unmedicated Parkinson's disease: evidence for a specific attentional dysfunction. Neuropsychologia 1989;27:1329-43.

49 Hassler R. Striatal control of locomotion, intentional actions and of integrating and perceptive activity. $\mathcal{F}$ Neurol Sciences 1978;36:187-224

50 Stam CJ, Visser SL, Op de Coul AAW, et al. Disturbed frontal regulation of attention in Parkinson's disease. Brain 1993;116:1139-58.

51 Cummings J. Depression and Parkinson's disease: a review. Am f Psychiatry 1992;149:443-54.

52 Hantz P, Caradoc-Davies G, Caradoc-Davies T, Weatherall M, Dixon G. Depression in Parkinson's disease. Am $\mathcal{F}$ Psychiatry 1994;151:1010-4.

53 Tanberg E, Larsen JP, Aarsland D, Cummings JL. The occurrence of depression in Parkinson's disease. Arch Neurol 1996;53:175-9.

54 Gotham AM, Brown RG, Marsden CD. Depression in Parkinson's disease: a quantitative and qualitative analysis. $\mathcal{F}$ Neurol Neurosurg Psychiatry 1986;49:381-9.

5 Starkstein SE, Preziosi TJ, Berthier ML, Bolduc PL, Mayberg HS, Robinson RG. Depression and cognitive mpairment in Parkinson's disease. Brain 1989;122:114153.

56 Sano M, Stern Y, Williams J, Cote L, Rosenstein R, Mayeux R. Co-existing dementia and depression in idiopathic Parkinson's disease. Arch Neurol 1989;46:1284-7.

57 Madeley P, Biggins CA, Boyd JL, Mindham RHS. Cognitive impairment and depression in Parkinson's disease. $\mathcal{F}$ Neurol Neurosurg Psychiatry 1991;54:941.

58 Lees AJ, Smith E. Cognitive deficits in the early stages of Parkinson's disease. Brain 1983;106:257-70

59 Boyd JL, Cruickenshank CA, Kenn CW, et al. Cognitive impairment and dementia in Parkinson's disease: a controlled study. Psychol Med 1992;21:911-21.

60 Tröster AI, Stalp LD, Paolo AM, Fields JA, Koller WC. Neuropsychological impairment in Parkinson's disease with and without depression. Arch Neurol 1995;5;1164-9.

61 O'Connor DW, Pollitt PA, Hyde JB, et al. The reliability and validity of the mini-mental state in a British community survey. F Psychiatr Res 1989;23:87-96.

62 Tombaugh TN, McIntyre NJ. The mini-mental state examination: a comprehensive review. f Am Geriatr Soc 1992;40:922-35.

63 Growdon JH, Corkin S. Cognitive impairment in Parkinson's disease. Adv Neurol 1987;45:383-92.

64 Lavernhe G, Pollak P, Brenier F, et al. Maladie d'Alzheimer et maladie de Parkinson. Différentiation neuropsychologique. Rev Neurol (Paris) 1989;145:24-30.

65 Sullivan EW, Sagar HJ, Gabrieli JDE, Corkin S, Growdon JH. Different cognitive profile on standard behavioral tests in Parkinson's disease and Alzheimer's disease. f Clin Exp Neuropsychol 1989;11:799-820.

66 Albert ML Subcortical dementia. In: Katzman R, Terry $\mathrm{RD}$, Bick KL, eds. Alzheimer's disease: senile dementia and related disorders (Aging, vol 7). New York: Raven Press, 1978:173-84.

67 Brown RG, Marsden CD. Subcortical dementia: the neuropsychological evidence. Neuroscience 1988;25:36387.

68 Massman PJ, Delis DC, Butters N, Levin BE, Salmon DP. Are all subcortical dementias alike? f Clin Exp Neuropsychol 1990;12:729-744.

69 Hughes T, Madeley P, Mindham RHS, Ross H, Finlayson G, Biggins CA. Subcortical dementia. Br f Psychiatry 1993;307:503

70 Elliott L, Lees AJ, Daniel SE. The neuropathology of cognitive impairment in Parkinson's disease. Mov Disord 1997;12(suppl 1):57

71 Pirozzolo FJ, Hansch EC, Mortimer JA, Webster DD, Kuskowski MA. Dementia in Parkinson's disease: a neuropsychological analysis. Brain Cogn 1982;1:71-83.

72 Masur DM, Sliwinski M, Lipton RB, Blau AD, Crystal HA Neuropsychological prediction of dementia and absence of dementia in the healthy elderly persons. Neurology 1994;44: 1427-32

73 Jacobs DM, Sano M, Dooneief G, Marder K, Bell KL, Stern Y. Neuropsychological detection and characterization of
preclinical Alzheimer's disease. Neurology 1995;45:957-62. 